\title{
MRI morphometric characterisation of the paediatric cervical spine and spinal cord in children with MPS IVA (Morquio-Brailsford syndrome)
}

\author{
Guirish A. Solanki • William B. Lo • Christian J. Hendriksz
}

Received: 10 October 2012 / Revised: 1 January 2013 / Accepted: 7 January 2013 /Published online: 13 February 2013

(C) The Author(s) 2013. This article is published with open access at Springerlink.com

\begin{abstract}
Nearly all children with MPS IVA develop skeletal deformities affecting the spine. At the atlanto-axial spine, odontoid hypoplasia occurs. GAG deposition around the dens, leads to peri-odontoid infiltration. Transverse/alar ligament incompetence causes instability. Atlanto-axial instability is associated with cord compression and myelopathy, leading to major morbidity and mortality. Intervention is often required. Does the presence of widened bullet shaped vertebra in platyspondily encroach on the spinal canal and cause spinal stenosis in MPS IVA? So far, there have been no standardised morphometric measurements of the paediatric MPS IVA cervical spine to evaluate whether there is pre-existing spinal stenosis predisposing to compressive myelopathy or whether this is purely an acquired process secondary to instability and compression. This study provides the first radiological quantitative analysis of the cervical spine and spinal cord in a series of affected children. MRI morphometry indicates that the MPS IVA spine is
\end{abstract}

Communicated by: Ed Wraith

G. A. Solanki $(\bowtie)$

Department of Paediatric Neurosurgery, Birmingham Children's

Hospital NHS Foundation Trust, Steelhouse lane,

Birmingham B4 6NH, UK

e-mail: guirish.solanki@bch.nhs.uk

G. A. Solanki

School of Clinical and Experimental Medicine, College of Medical and Dental Sciences, University of Birmingham, Birmingham, UK

W. B. Lo

Birmingham Children's Hospital NHS Foundation Trust, Birmingham, UK

C. J. Hendriksz

Manchester Academic Health Science Centre,

University of Manchester, Manchester, UK narrower at C1-2 level giving an inverted funnel shape. There is no evidence of a reduction in the Torg ratio (canal-body ratio) in the cervical spine. The spinal canal does not exceed $11 \mathrm{~mm}$ at any level, significantly smaller than normal historical cohorts $(14 \mathrm{~mm})$. The sagittal diameter and axial surface area of both spinal canal and cord are reduced. C1-2 level cord compression was evident in the canal-cord ratio but the Torg ratio was not predictive of cord compression. In MPS IVA the reduction in the space available for the cord (SAC) is multifactorial rather than due to congenital spinal stenosis.

$\begin{array}{ll}\text { Abbreviations } \\ \text { AAS } & \text { Atlanto-axial subluxation } \\ \text { AAI } & \text { Atlanto-axial instability } \\ \text { ADI } & \text { Atlanto-dens interval } \\ \text { MRI } & \text { Magnetic resonance imaging } \\ \text { PADI } & \text { Posterior atlanto-dens interval } \\ \text { KS } & \text { Keratan sulphate } \\ \text { C6S } & \text { Chondroitin } 6 \text { sulphatase } \\ \text { CBR } & \text { Sagittal (AP) ratio of spinal canal to vertebral } \\ & \text { body } \\ \text { RAPTD } & \begin{array}{l}\text { Ratio of AP to Transverse Diameter of Spinal } \\ \text { cord }\end{array} \\ \text { AP } & \text { Antero-posterior } \\ \text { TD } & \text { Transverse Diameter }\end{array}$

\section{Introduction}

Mucopolysaccharidosis type IVA (MPS IVA) is an autosomal recessive hereditary disease with deficiency in $\mathrm{N}$-acetyl galactosamine-6-sulphatase.

The first patients with mucopolysaccharidosis (MPS) were described by Hunter and Hurler in 1900. It took 
another three decades before Luis Morquio, a paediatrician in Uruguay, and James Frederick Brailsford, a radiologist at the Children's Hospital in Birmingham, England, simultaneously described a clinical series and radiological features of cases of what is now known as MPS IV or eponymously as Morquio-Brailsford syndrome (Brailsford 1929; Morquio 1929). MPS IV patients share a cluster of skeletal anomalies known as dysostosis multiplex that are common with other MPS types. In 1957, Dorfman and Lorincz developed clinical assays to detect urinary mucopolysaccharides, permitting early and easy laboratory diagnosis and differentiation of the MPS types and severity of their biochemical abnormality (Dorfman and Lorincz 1957).

Infants with Morquio-Brailsford syndrome are normal at birth and by 18 to 20 months of age develop characteristic clinical features affecting multiple systems, including the skeletal, visual, auditory, gastro-intestinal, cardiovascular and respiratory systems (Hendriksz et al 2012). Because $\mathrm{KS}$ and $\mathrm{C6S}$ are major components of proteoglycans in cartilage and bone, skeletal dysplasia is the major manifestation in MPS IVA affected children (Northover et al 1996; Tomatsu et al 2011; Wraith 1995). Short trunk dwarfism and genu valgus are characteristic features. Dens hypoplasia and/or os odontoideum are present in nearly all patients with varying degrees of cord compression due to anterior soft tissue mass (composed of GAGs) and indentation by the posterior arch of the atlas (Hughes et al 1997).

The pathology of MPS IVA suggests a spondyloepiphysealmetaphyseal dysplasia. The epiphyseal growth plate which lies between the metaphysis and the epiphysis fails to develop due to the enzymatic block. Growth slows down by 18 months and arrests at around 8 years of age with a definitive size of $1 \mathrm{~m}$ to $1.50 \mathrm{~m}$, depending on the severity of the disease. From the age of 5 to 6 years, hypoplasia of the odontoid process combined with joint hyperlaxity leads to an instability at the level of the first two cervical vertebrae, with a risk of spinal cord compression. An 'os odontoideum' is sometimes present, as in many other skeletal dysplasias. This is due to a partially cartilaginous dens tip, fracture of which may not be visible on radiographs. In addition, the ring of $\mathrm{C} 1$ is potentially unstable because of failure of ossification anteriorly or posteriorly or both.

Skeletal dysplasia, or incomplete ossification of the cartilaginous vertebral body, results in characteristic cervical and thoracolumbar deformities. In the cervical spine, the presence of os odontoideum, the incomplete ossification of the atlas, odontoid hypoplasia and resultant laxity of the transverse and alar ligaments, lead to atlanto-axial subluxation (AAS) and atlanto-axial instability (AAI) (Stevens et al 1991). In addition, there is anterior extra-dural tissue thickening. The combination of these cervical abnormalities leads to cord compression, resulting in myelopathy and severe morbidity and mortality. A significant proportion of patients with MPS IVA require surgical treatment, in the form of correction of subluxation and fusion.

Measurements of the spine have been limited to qualitative reporting of stenosis-compression or instability-compression effects to the spinal cord at specific sites. Radiographic measurements of the vertebral body and the spinal canal are normally used for diagnosis of congenital stenosis. While in the lumbar spine the inter-pedicular distance has been used to evaluate spinal canal change for example in tumours or congenital stenosis, the inter-pedicular distance is of little value in studying the cervical spine (Hinck et al 1962). The pedicles overlap the vertebra and are often not demonstrable above C5. Cervical pedicles do not appear oval on the AP views as they are oblique on the sagittal plane. Cervical inter-pedicular measurements are therefore rarely used for assessment of the cervical canal dimensions. The sagittal diameter of the cervical spinal canal has been found to be more reliable. The ratio of the sagittal diameters of the spinal canal and the vertebral body is a radiographic measure of spinal canal stenosis (Pavlov et al 1987). Significant spinal stenosis and an increased risk for neurologic injury occur when the ratio is less than 0.80 or 0.70 . Previous studies have shown that reduced spinal cord area before decompression would indicate poor surgical outcomes (Fujiwara et al 1989; Fukushima et al 1991; Koyanagi et al 1993; Matsumoto et al 2000). Cervical spinal cord dimensions have also been analysed in normal subjects, the most recent study involving 1200 subjects (Ishikawa et al 2003; Kato et al 2012; Yanase et al 2006). To date, however, no study has been carried out to analyse the morphometry of the cervical spinal cord of children with MPS IVA.

\section{Patients and methods}

Seventeen children (nine males, eight females) with MPS IVA investigated with MRI of the spine and treated or followed up in our institute between 2003 and 2010 were evaluated in this study. Their mean age was 6.9 years and median age was 5.8 years (range: $1-17$ years). All children underwent magnetic resonance imaging (MRI) of the cervical spine using a 1.5 Tesla GE or Siemens scanner. During MRI, the patients were in their most comfortable posture in the supine position, normally in neutral position. T1-weighted sagittal and axial images with a slice thickness of $3 \mathrm{~mm}$ of Digital Imaging and Communications in Medicine (DICOM) standard were used for analysis using available Picture Archiving and Communications System (PACS) measurement software (Agfa Gevart).

All linear measurements and the axial transverse area measurements were taken at the mid-vertebral levels. For measurements of $\mathrm{C} 1$ and $\mathrm{C} 2$, the midpoint of atlas $(\mathrm{C} 1)$ ring and the axis $(\mathrm{C} 2)$ mid-body were used as the references. The cross-sectional surface areas of the spinal canal and spinal cord were measured by tracing the perimeter of the 
structures with a cursor, a function of PACS. The morphometric information obtained included: spinal canal to vertebral body ratio (CBR), also known as the Torg ratio, which is calculated by dividing the antero-posterior diameter of the spinal canal by that of the vertebral body (Fig. 1), anteroposterior (AP) diameter of the spinal canal and cord (Fig. 2), ratio of the antero-posterior diameter to the transverse diameter (RAPT) of the cord and cross-sectional surface area of the dural tube and spinal cord (Fig. 3). The measurements of the vertebral bodies include both the bony anatomy and soft tissue. On the other hand, when measuring the space within the spinal canal, the dural tube, freed of epidural soft tissue, was measured, rather than the bony spinal canal. Such methodology reflects the true space around the spinal cord. All measurements were performed and agreed by two investigators. Statistical analyses were performed using Minitab $^{\circledR}$ and Excel $^{\circledR}$ programmes. Analysis of variance (ANOVA) and generalised linear model analysis were used.

\section{Results}

\section{Inter-subject variation}

Using ANOVA, it is demonstrated that the inter-subject differences in all measured or calculated parameters are significant $(p<0.010)$. To assess whether such differences are due to different ages, a generalised linear model analysis was used. Inter-subject variations in CBR, AP spinal canal diameter and AP spinal cord diameter are not age-dependent. However, the spinal cord cross-sectional area is inversely

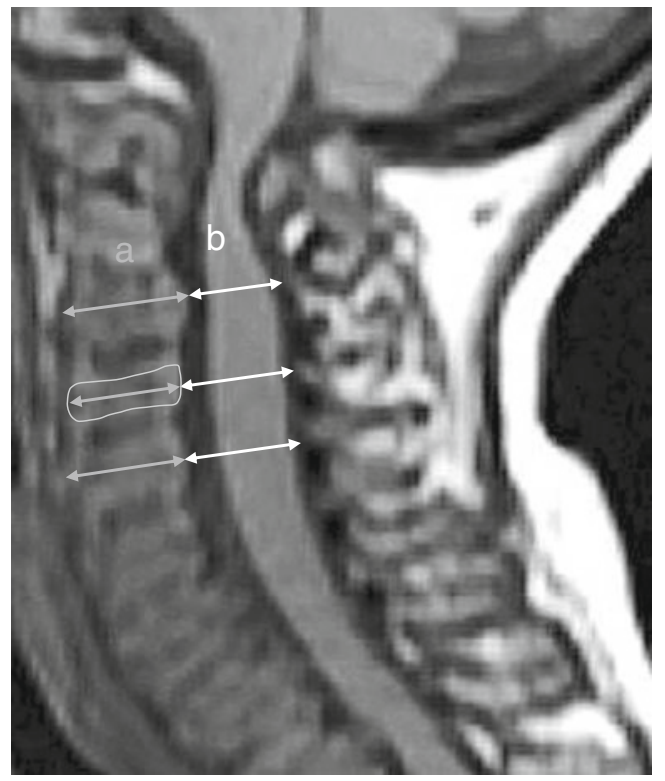

Fig. 1 Sagittal section of T1-weighted MRI showing the measurements of the AP diameter of the vertebral bodies (grey lines, a) and spinal canal (white lines, $\mathbf{b}$ ), at the mid-vertebral levels. $\mathrm{CBR}=\mathrm{b} / \mathrm{a}$

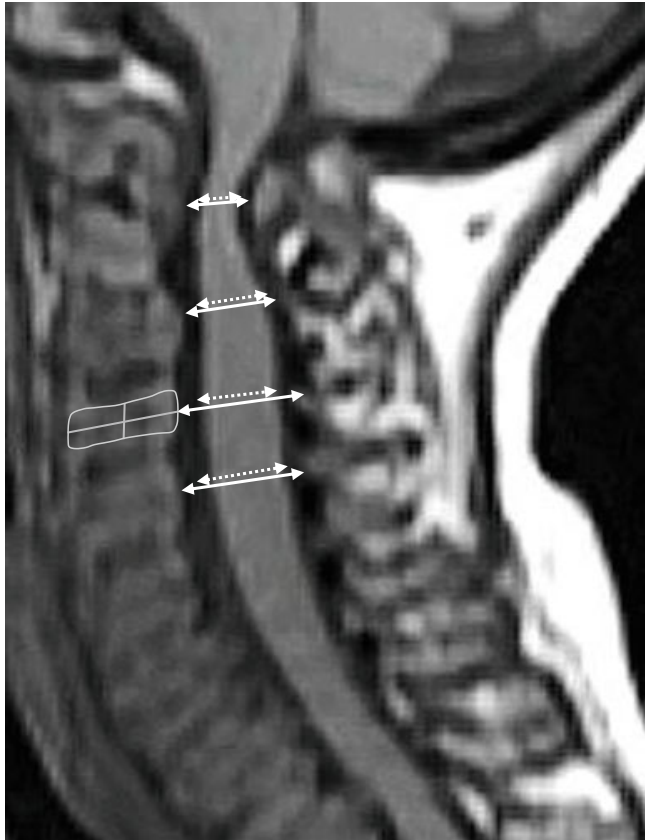

Fig. 2 Sagittal section of T1-weighted MRI showing the measurements of the AP diameter of the spinal canal (white lines) and spinal cord (white dotted lines). Note that the measurements are taken at the mid-vertebral levels (grey lines)

correlated with age (coefficient $-0.7078, p=0.038$ ) (see later Results section). There is no significant difference between gender for CBR, AP cord diameter and cross-sectional area of the cord (Tables 1 and 2).

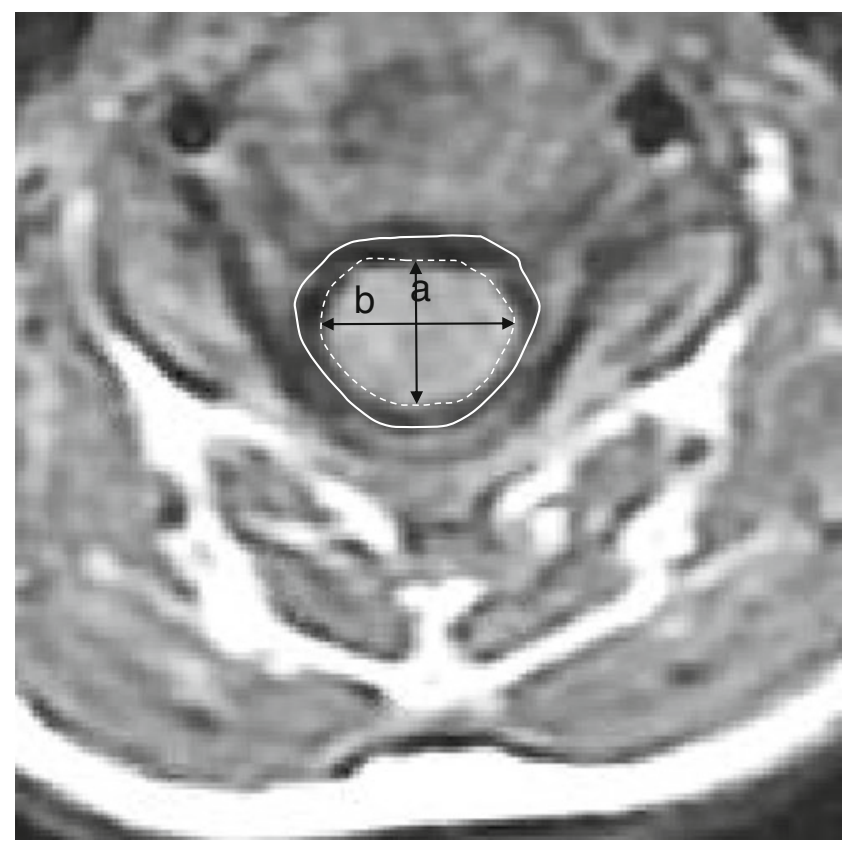

Fig. 3 Axial section of T1-weighted MRI showing the measurements of a antero-posterior diameter (black line, a) and transverse diameter (black line, $\mathbf{b}$ ) of the cord, from which RAPT is calculated and $\mathbf{b}$ crosssectional area of the spinal canal (white continuous line) and spinal cord (white dotted line) 
Table 1 Normal measurements of upper cervical spine on conventional radiographs

\begin{tabular}{lll}
\hline Measurement & $\begin{array}{l}\text { Radiographic } \\
\text { value }(\mathrm{mm})\end{array}$ & $\begin{array}{l}\text { MDCT } \\
\text { value }(\mathrm{mm})\end{array}$ \\
\hline $\begin{array}{l}\text { Basion to dens interval } \\
\text { With ossification }\end{array}$ & $<12$ & $<9.5$ \\
Without ossification & $<12$ & $<11.6$ \\
Basion to axis interval & $<1$ & $<12$ \\
Powers ratio & $<5$ & $<0.9$ \\
Condylar (C0-C1) gap & $<12$ & $<5$ \\
C1-C2 interspinous distance & & $<2.5$ \\
$\begin{array}{l}\text { Atlanto-occipital interval } \\
\text { Atlanto-dental interval } \\
\quad \text { predental space) }\end{array}$ & $<5$ in $\leq 8$ years old & $<2.6$ \\
Atlanto-axial interval & $<3$ in $>8$ years old & \\
\hline
\end{tabular}

Spinal canal to vertebral body ratio (CBR)

This is the radiographic equivalent of Torg ratio (Pavlov et al 1987) on MRI (Table 6). The mean CBRs are 0.84 at $\mathrm{C} 2$ vertebral level, 0.80 at $\mathrm{C} 3,0.84$ at $\mathrm{C} 4,0.94$ at $\mathrm{C} 5,0.96$ at $\mathrm{C} 6$ and 0.84 at $\mathrm{C} 7$ (Table 2). There is no CBR for $\mathrm{C} 1$ because the atlas does not have a body. The CBR is lowest at C3. The variations between levels and subjects are statistically significant ( $p=0.010$ and $p=0.005$, respectively). However, the variation is not age-dependent $(p=0.869)$. As the measurements are taken from MR images, the vertebral body component for the calculation of CBR includes both the bone and the soft tissue (posterior longitudinal ligament) attached to it. Such methodology provides more relevant information regarding the pathological spine and functional spinal canal stenosis, although it varies from the original description of CBR which applied to lateral radiographs and did not include soft tissue (Torg ratio). In this group of children we measured the $\mathrm{CBR}$ at $\mathrm{C} 3$ as less than that at $\mathrm{C} 2$, reflecting a combination of atlanto-axial instability with horizontal subluxation, deposition of GAGs in peri-odontoid tissues and incompetent transverse and alar ligaments. Despite these findings the overall CBR on MRI for all levels indicated that in MPS IVA children there is little evidence of (congenital) spinal stenosis as defined by a canal body ratio less than 0.82 .

AP spinal canal and spinal cord diameters

The comparative AP diameters of the cervical spinal canal and the cord are summarised in Table 3 and Figs. 4 and 5 . There is a gradual, statistically significant reduction of AP diameter of the spinal canal towards the superior cervical spine $(p<0.001)$, corresponding to the distribution of the abnormal soft tissue. This reduction is associated with a similar reduction of AP diameter of the spinal cord at the corresponding level. The difference in the diameters is the smallest at $\mathrm{C} 3(1.5 \mathrm{~mm})$ and largest at C6 $(2.8 \mathrm{~mm})$. These changes particularly in the axial spine are indicative of a reduction of the space available for the cord.

Cross-sectional surface area for the spinal canal and cord

The cross-sectional surface areas of the spinal canal and cord are summarised in Table 4 and Figs. 5 and 6. There is a narrowing of spinal canal at $\mathrm{C} 3$ level, although the variation in spinal canal cross-sectional surface area is not significant. On the other hand, the spinal cord is narrowest at $\mathrm{C} 1 / 2$ level (56 and $51 \mathrm{~mm}^{2}$, respectively), although again the inter-level variation in area is not significant $(p=0.191)$. However, there is a significant inter-level variation in the ratio of the spinal canal to cord transverse area $(p=0.014)$ (Figs. 7 and 8$)$. C2 has the lowest ratio at 0.44 . The relative uniform spinal cord surface area along the cervical spine is in contrast with the marked reduction AP diameter at $\mathrm{C} 1 / 2$ levels. Such observation can be explained by the change in cross-section of the cord, as expressed by the reduction of RAPT at higher cervical levels ( 0.59 at $\mathrm{C} 1$ and 0.52 at $\mathrm{C} 2$ compared to above 0.64 from $\mathrm{C} 3$ to $\mathrm{C} 7)(p<0.001)$ (Table 5). When compressed in an antero-posterior direction, the spinal cord is seen to be
Table 2 Canal body ratio, antero-posterior cord diameter and cross-sectional area of the cord from $\mathrm{C} 1$ to $\mathrm{C} 7$ levels for male and female subjects

\begin{tabular}{|c|c|c|c|c|c|c|c|}
\hline \multirow[t]{2}{*}{ Level } & \multicolumn{3}{|c|}{ Canal body ratio } & \multicolumn{2}{|c|}{ Antero-posterior cord diameter (mm) } & \multicolumn{2}{|c|}{ Cross-sectional area $\left(\mathrm{mm}^{2}\right)$} \\
\hline & All & Male & Female & Male & Female & Male & Female \\
\hline $\mathrm{C} 1$ & - & - & - & 6.2 & 6.0 & 58 & 53 \\
\hline $\mathrm{C} 2$ & 0.84 & 0.84 & 0.83 & 5.5 & 6.3 & 48 & 56 \\
\hline $\mathrm{C} 3$ & 0.80 & 0.76 & 0.84 & 7.0 & 7.0 & 60 & 62 \\
\hline $\mathrm{C} 4$ & 0.84 & 0.79 & 0.90 & 7.5 & 6.9 & 62 & 63 \\
\hline $\mathrm{C} 5$ & 0.94 & 0.94 & 0.95 & 7.3 & 7.3 & 58 & 63 \\
\hline C6 & 0.96 & 0.97 & 0.94 & 7.8 & 7.8 & 59 & 66 \\
\hline C7 & 0.84 & 0.82 & 0.85 & 7.9 & 8.4 & 54 & 61 \\
\hline
\end{tabular}


Table 3 Antero-posterior diameters of spinal canal and spinal cord from $\mathrm{C} 1$ to $\mathrm{C} 7$

$S D$ standard deviation

\begin{tabular}{lccccc}
\hline \multirow{2}{*}{ Level } & \multicolumn{2}{c}{ Spinal canal AP diameter $(\mathrm{mm})$} & & \multicolumn{2}{c}{ Spinal cord AP diameter $(\mathrm{mm})$} \\
\cline { 2 - 3 } \cline { 5 - 6 } & \multicolumn{2}{c}{ Mean \pm SD } & & Mean \pm SD & Median \\
\hline C1 & $8.3 \pm 2.4$ & 8.8 & & $6.1 \pm 1.2$ & 6.2 \\
C2 & $8.4 \pm 1.8$ & 8.8 & & $5.9 \pm 1.3$ & 5.9 \\
C3 & $8.6 \pm 1.3$ & 8.6 & & $7.0 \pm 1.4$ & 7.0 \\
C4 & $8.8 \pm 1.2$ & 9.0 & & $7.2 \pm 1.1$ & 7.2 \\
C5 & $10.0 \pm 1.1$ & & & $7.3 \pm 1.6$ & 7.0 \\
C6 & $10.7 \pm 1.4$ & 10.7 & & $7.9 \pm 2.0$ & 7.7 \\
C7 & $10.2 \pm 1.0$ & 10.3 & & $8.1 \pm 1.9$ & 7.5 \\
\hline
\end{tabular}

displaced into the potential space of the lateral recesses, with an associated change in shape from round to oval, similar to cord compression in cervical spondylosis.

The inter-subject variation in spinal cord cross-sectional surface area is statistically significant $(p<0.001)$, like the CBR, AP canal and cord diameters. However, while the variations of other parameters are not age-dependent, the spinal cord surface area is inversely correlated with the age, with a coefficient of $-0.7078 \mathrm{~mm}^{2} /$ year $(p=0.038)$. In other words, the cervical spinal cord is narrower in older children with Morquio-Brailsford syndrome.

\section{Discussion}

Spinal canal stenosis

While the definition of spinal stenosis is easy, the precise morphometric measure for spinal stenosis

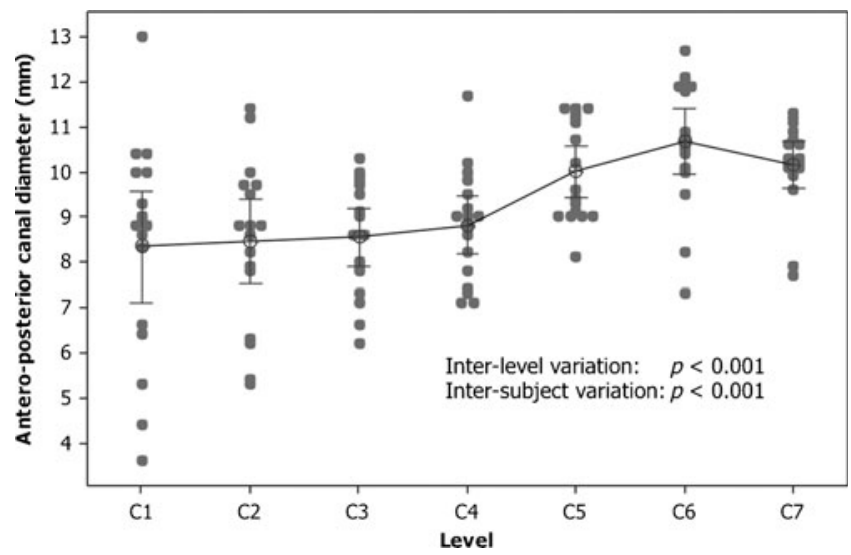

Fig. 4 Individual value plot of AP canal diameter. Note the median value does not exceed $11 \mathrm{~mm}$ (normal $14 \mathrm{~mm}$ ) and the much narrower $\mathrm{C} 1$ and C2 AP diameters. This "inverse funnel shape" appearance of the spinal canal is due to C1-2 instability and atlanto-axial subluxation in these children. Each grey round dot represents the CBR of a particular level in a particular patient. The vertical lines represent the $95 \%$ confidence levels, inter-level and inter-subject variations are statistically significant $(p<0.001, p<0.001$, respectively) remains elusive. A proliferation of radiological imaging options while welcome, does not help and adds to the difficulties of a single standard defining measurement. The ratio of the sagittal diameters of the spinal canal and the vertebral body, known as the Torg ratio, was proposed in 1987 as a radiographic measure of spinal canal stenosis (Pavlov et al 1987). Significant spinal stenosis and an increased risk for neurologic injury occur when the ratio is less than 0.80 or 0.70 respectively (Castro et al 1997; Pavlov et al 1987; Torg et al 1997). Compared with the spinal-canal diameter, the Torg ratio is a more accurate indicator of spinal stenosis using radiographs. The measure however is inconsistent between gender (males have larger values) and athletes have larger vertebral bodies than non-athletes (Blackley et al 1999; Tierney et al 2002). This results in smaller Torg ratios and false positive diagnosis of stenosis (Solanki 2011).

There is a gender discrepancy of canal/body ratio but this discrepancy seems to appear after the age of 15 years. The canal/body ratio was similar in both sexes until 15 years of age but became consistently smaller in males than in

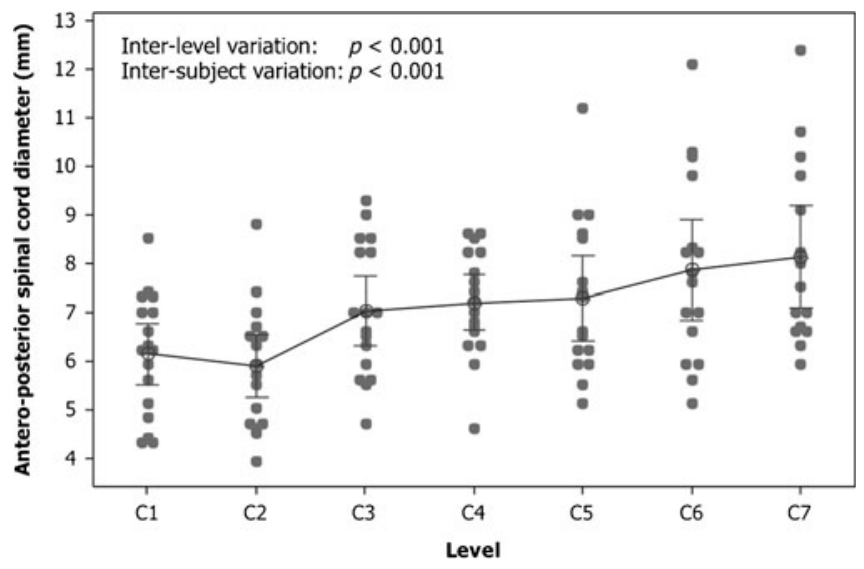

Fig. 5 Individual value plot of AP cord diameter. Note the smaller diameter at $\mathrm{C} 1$ and $\mathrm{C} 2$ levels, the "inverse funnel shape" appearance of the spinal cord 
Table 4 Cross-sectional areas of spinal canal and spinal cord, and canal to cord area ratios from $\mathrm{C} 1$ to $\mathrm{C} 7$

\begin{tabular}{|c|c|c|c|c|c|c|}
\hline \multirow[t]{2}{*}{ Level } & \multicolumn{2}{|c|}{$\begin{array}{l}\text { Spinal canal cross-sectional } \\
\text { area }\left(\mathrm{mm}^{2}\right)\end{array}$} & \multicolumn{2}{|c|}{$\begin{array}{l}\text { Spinal cord cross-sectional } \\
\text { area }\left(\mathrm{mm}^{2}\right)\end{array}$} & \multicolumn{2}{|c|}{$\begin{array}{l}\text { Spinal cord to canal } \\
\text { area ratio }\end{array}$} \\
\hline & Mean \pm SD & Median & Mean \pm SD & Median & Mean & Median \\
\hline $\mathrm{C} 1$ & $130 \pm 43$ & 116 & $56 \pm 13$ & 54 & 0.45 & 0.45 \\
\hline $\mathrm{C} 2$ & $121 \pm 34$ & 114 & $51 \pm 17$ & 51 & 0.44 & 0.40 \\
\hline $\mathrm{C} 3$ & $107 \pm 24$ & 109 & $61 \pm 16$ & 65 & 0.57 & 0.55 \\
\hline $\mathrm{C} 4$ & $119 \pm 19$ & 116 & $62 \pm 14$ & 65 & 0.53 & 0.51 \\
\hline $\mathrm{C} 5$ & $128 \pm 24$ & 129 & $60 \pm 19$ & 59 & 0.47 & 0.45 \\
\hline C6 & $135 \pm 36$ & 133 & $62 \pm 21$ & 64 & 0.46 & 0.45 \\
\hline C7 & $114 \pm 32$ & 106 & $57 \pm 19$ & 56 & 0.50 & 0.50 \\
\hline
\end{tabular}

females through to adulthood at every measured segment (Robinson et al 1990). The present review mainly precedes the greater growth spurt of the male vertebral body observed at puberty thought to lead to the sex discrepancy of the canal/body ratio thereafter.

More recently attention has shifted to using the ratio of the sagittal spinal canal to spinal cord on MR imaging to avoid the magnification errors common with radiographs and variations related to vertebral bone size (Herzog et al 1991; Solanki 2011) (Tierney et al 2002; Torg et al 1997). In addition, MR imaging now allows accurate measurements in the axial plane. The space available for the cord, the cross-sectional surface area and volume of the spinal cord within the spinal canal itself can be defined and has been quantified in MorquioBrailsford and MPS VI (Solanki 2011). While the osseous dimensions can be appreciated by XR or CT, the space available for the cord (SAC) is difficult to evaluate except on MR.

When evaluating cord compression, measurements of spinal stenosis using $\mathrm{x}$-rays and $\mathrm{CT}$ alone may be less helpful in patients with MPS IVA and other MPS conditions. These patients have a significant soft tissue mass component to their spinal stenosis and the ensuing cord

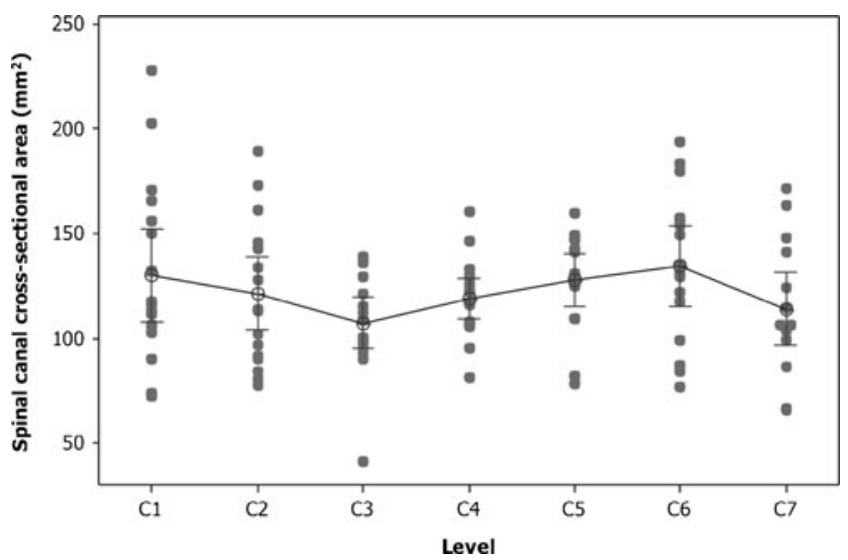

Fig. 6 Cross-sectional surface area of spinal canal compression may be underestimated unless a CT scan soft tissue filter or protocol is used. Because MRI demonstrates the spinal cord and spinal canal directly, it is the most useful technique in diagnosing stenosis and cord compression in this region of the spine. To date, no study has compared the SAC measurement for determining stenosis with the Torg ratio (Solanki 2011).

Spinal canal and cord measurements

In normal adults, the spinal canal at $\mathrm{C} 1$ level measures $22 \mathrm{~mm}(20-26 \mathrm{~mm})$, decreasing to $20 \mathrm{~mm}$ at $\mathrm{C} 2$, and between 14 and $22 \mathrm{~mm}$ between C3-7. The sagittal cord at C1 measures $10.4 \mathrm{~mm}(7-11 \mathrm{~mm})$, decreasing to $9 \mathrm{~mm}(7-$ $10 \mathrm{~mm})$ at $\mathrm{C} 2$, and averages $8.5 \mathrm{~mm}(6-9 \mathrm{~mm})$ between $\mathrm{C} 3-$ 7. The transverse cord measures $10-14 \mathrm{~mm}$. The reserve area for the spinal cord should include a subarachnoid space for CSF. A reduced cross-sectional surface area of the cord $\left(30-44 \mathrm{~mm}^{2}\right)$ is known to correlate with poor outcome. An antero-posterior (AP) spinal canal diameter of about $12 \mathrm{~mm}$ is probably associated with symptoms, and of less than $14 \mathrm{~mm}$ is associated with cervical stenosis at any segment

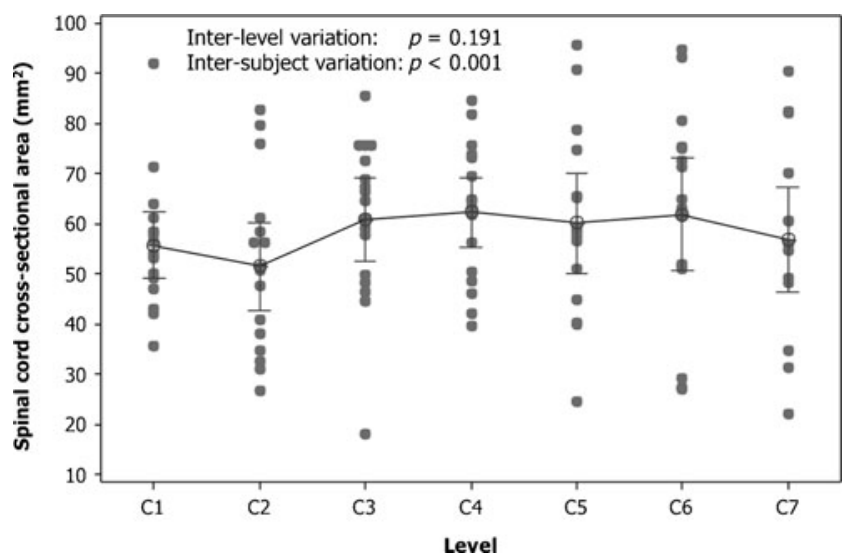

Fig. 7 Cross-sectional surface area of spinal cord 


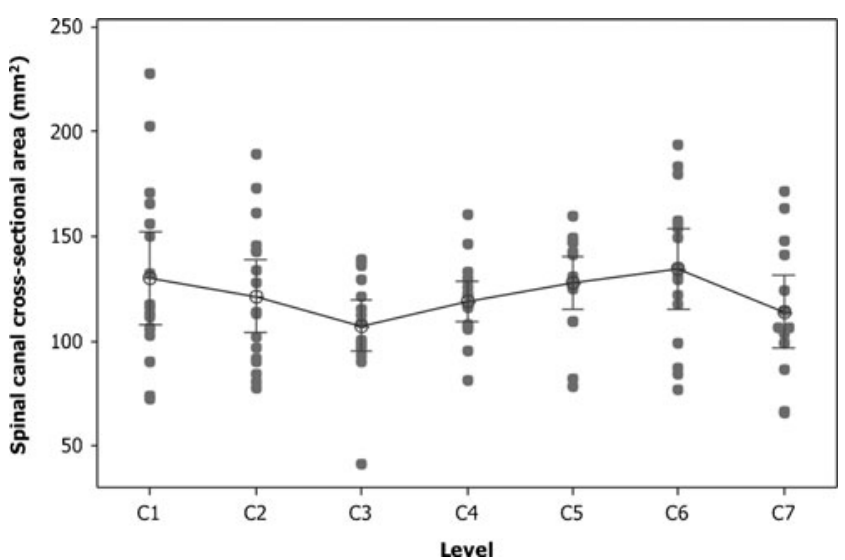

Fig. 8 Spinal cord to canal transverse area ratio from $\mathrm{C} 1$ to $\mathrm{C} 7$ levels

(Kessler 1975). In adults, a spinal canal of about 15-16 mm is usually asymptomatic.

Other normal measurements of upper cervical spine on conventional radiographs and multi-dimensional $\mathrm{CT}$ (MDCT) are compared in Table 1.

\section{Stenosis in MPS IVA}

In MPS IVA, stenosis of the spinal canal may be multisegmental or segmental. At each level the stenosis may be central, lateral recess or foraminal when there is encroachment of the central space, of the lateral recess or of the root exit foraminae respectively. The most likely sites for spinal cord compression are where the cord is normally at its thickest, in the axial cervical spine (C1-C2), brachial expansion in the subaxial spine $(\mathrm{C} 4-\mathrm{C} 7)$, and at the conus medullaris (L1-L2). Unfortunately it is also at the vicinity of these sites that the deposition of glycosaminoglycans seems to be greater such as in the $\mathrm{C} 1-\mathrm{C} 2$ joint. Also, kyphotic curves are the most pronounced such as in the cervicothoracic and the thoraco-lumbar junctions.

Table 5 Spinal cord antero-posterior diameter, transverse diameter and RAPT

\begin{tabular}{lccc}
\hline Level & $\begin{array}{l}\text { Cord antero-posterior } \\
\text { diameter }(\mathrm{mm})\end{array}$ & $\begin{array}{l}\text { Cord transverse } \\
\text { diameter }(\mathrm{mm})\end{array}$ & $\begin{array}{l}\text { Cord } \\
\text { RAPT }\end{array}$ \\
\hline $\mathrm{C} 1$ & 6.1 & 10.8 & 0.59 \\
$\mathrm{C} 2$ & 5.9 & 11.3 & 0.52 \\
$\mathrm{C} 3$ & 7.0 & 11.0 & 0.65 \\
$\mathrm{C} 4$ & 7.2 & 10.6 & 0.68 \\
$\mathrm{C} 5$ & 7.3 & 10.2 & 0.72 \\
$\mathrm{C} 6$ & 7.9 & 9.5 & 0.84 \\
$\mathrm{C} 7$ & 8.1 & 9.6 & 0.99 \\
\hline
\end{tabular}

$R A P T$ ratio of the antero-posterior diameter to the transverse diameter (= cord antero-posterior diameter/cord transverse diameter)
In the axial cervical spine (C1-C2 level) the spinal cord is at particular risk. The thickening of the connective tissues within the bony spinal canal, particularly the anterior soft tissue deposition of GAGs in the cruciate ligament and the indentation by the posterior arch of the atlas, further compound cord compression. Dens hypoplasia increases instability which can lead to secondary intermittent or fixed compression.

In the subaxial spine (C3-7), it is not uncommon to see multi-segmental thickening of the posterior longitudinal ligament and ligamentum flavum encroaching on the mid-cervical expansion of the cervical cord. Below this level we often see a prominent cervico-thoracic curve, giving the typical swanneck appearance in these children in an attempt to maintain cervical extension, a position more protective of the cervical spinal cord than in neutral or flexion positions.

Multi-segmental stenosis is associated with generalized thickening of the posterior longitudinal ligament perhaps due to GAG (glycosaminoglycan) deposition. Thickening of the posterior longitudinal ligament and ligamentum flavum becomes more prominent with increasing age and contributes to functional canal stenosis and cord compression.

Myelopathy

Cervical myelopathy secondary to cord compression results in severe morbidity. In a previous study of the normal adult population, a canal/body ratio (CBR) of $<0.82$ has been found to be a useful criterion for cervical canal stenosis with a sensitivity and specificity of $92 \%$ and $94 \%$, respectively (Pavlov et al 1987). In subsequent radiological and cadaveric studies of healthy subjects, the average AP diameters of the vertebral body and spinal canal, the CBR and the transverse area of the spinal cord were measured and calculated (Hukuda and Kojima 2002; Ishikawa et al 2003; Kameyama et al 1994; Kameyama et al 1996; Yanase et al 2006). Combined with clinical context, such information aids formulating management plan and predicting diagnosis.

Children with MPS IVA develop multisystem abnormalities (Hendriksz et al 2012). Most of them develop progressive cervical and lumbosacral deformities, which result in neurological sequelae. In previous studies, asymptomatic children who underwent prophylactic occipito-cervical fusion achieved the best

Table 6 Pavlov's Canal/Body Ratios of Normal Controls in the 1987 study

\begin{tabular}{lccl}
\hline & Male controls $(n=49)$ & Female controls $(n=25)$ & $P$ value \\
\hline C3 & $1.008 \pm 0.118$ & $1.018 \pm 0.106$ & NS \\
C4 & $0.973 \pm 0.110$ & $1.011 \pm 0.071$ & NS \\
C5 & $0.975 \pm 0.091$ & $1.016 \pm 0.057$ & NS \\
C6 & $0.978 \pm 0.104$ & $1.016 \pm 0.078$ & NS \\
\hline
\end{tabular}


clinical outcome and remained the most mobile (Crockard and Stevens 1996; Stevens et al 1991). The same studies included qualitative and some quantitative analyses of the cervical column. This is the first comprehensive morphometric study on the cervical spine of patients with MPS IVA.

The CBRs of children of the present study are similar to the data in a previous study of 229 healthy subjects from 11 to 72 years of age (Table 6) (Ishikawa et al 2003). However, the same study showed that the CBR reduces with age, and therefore the CBRs of healthy subjects under 20 years of age could be higher, although the study did not provide data subsets of the younger age group.

Thickening of anterior extra-dural tissue is the main cause of cord compression at the upper cervical column. This could be non-ossified cartilage, reactive changes and thickening of the posterior longitudinal ligament. Our measurements showed that at $\mathrm{C} 1$ and $\mathrm{C} 2$ levels, the AP diameters of the spinal canal are smaller than $\mathrm{C} 3$ to $\mathrm{C} 7$ ( 8.3 and $8.4 \mathrm{~mm}$ compared to 8.6 to $10.7 \mathrm{~mm}$ ) (Table 2, Figs. 4 and 5).

The transverse area is also slightly reduced at the $\mathrm{C} 1 / 2$ levels. Otherwise, it remains consistent in the subaxial levels. Previous studies showed that adult patients with myelopathy have poorer prognosis if the spinal cord transverse area is less than 30 to $45 \mathrm{~mm}^{2}$ (Fujiwara et al 1989; Fukushima et al 1991). Interestingly, in this study, the narrowest level is C2, measuring $51 \pm 17 \mathrm{~mm}^{2}$. This area is larger than the area indicative of poor outcome. However, it is much reduced compared to the young adult average of $77.9 \mathrm{~mm}^{2}$ for male and $72.4 \mathrm{~mm}^{2}$ for female (Kato et al 2012) (Table 3, Fig. 7).

\section{Future directions}

This study indicates that there is an element of compression particularly in the upper cervical spine related to atlanto-axial instability and GAG deposition. A further study to elucidate these measurements in earlier non-compressed spines is planned along with morphometry of the whole spine.

There is now early evidence that cord compression can be adequately measured both in sagittal and transverse diameters. A ratio of the spinal canal to cord dimensions can be consistently and reliably obtained.

The use of these critical measurements when combined with clinical evidence of disease progression may allow development of a prognostic model for effective and timely spinal decompression and or stabilization

\section{Conclusion}

In this MRI study, children with MPS IVA generally have a normal spinal canal to vertebral body ratio and therefore strictly speaking do not have congenital spinal stenosis as part of the skeletal dysplasia and platyspondily universally found in MPS IVA. However because of the reduced dimensions of both the spinal canal and spinal cord found in MPS IVA affected children compared to normal adults, the value of this ratio in predicting cord compression is suspect.

There is a reduction in the antero-posterior canal diameter at $\mathrm{C} 1-\mathrm{C} 2$, and a relatively reduced $\mathrm{C} 1-\mathrm{C} 2$ spinal cord volume. The cord volume was significantly smaller than their healthy counterparts and was measured just above levels considered to have poor prognosis for recovery of cord compression. This study has introduced a number of measurement methods and has shown that these methods are useful in evaluating the extent of cord compression and may be clinically applied in the management and prognostication of compressive myelopathy in MPS IVA children.

Acknowledgments We are grateful to colleagues in the departments of inborn errors of metabolism, and radiology, Birmingham Children's Hospital for their support.

Competing interest G. A. Solanki, has received speaker's honorarium and travel support from BioMarin Pharmaceutical Inc. (BioMarin). William Lo has no conflict of interest and no disclosures to make.

C. J. Hendriksz has received consulting fees, symposium support for himself and team personnel, and research grants from BioMarin, and has also been an investigator in MPSIVA clinical trials.

Open Access This article is distributed under the terms of the Creative Commons Attribution License which permits any use, distribution, and reproduction in any medium, provided the original author(s) and the source are credited.

\section{References}

Blackley HR, Plank LD, Robertson PA (1999) Determining the sagittal dimensions of the canal of the cervical spine. The reliability of ratios of anatomical measurements. J Bone Joint Surg Br 81(1):110-112

Brailsford J (1929) Chondro-osteo-dystrophy, roentgenographic and clinical features of a child with dislocation of vertebrae. Am J Surg 7:404-410

Castro FP, Ricciardi J, Brunet ME, Busch MT, Whitecloud TS (1997) Stingers, the Torg ratio, and the cervical spine. Am J Sports Med 25(5):603-608

Crockard HA, Stevens JM (1996) Occipito-atlanto-axial fusion in Morquio-Brailsford syndrome. A 10-year experience. J Bone Joint Surg Br 78:307-313

Dorfman A, Lorincz A (1957) Occurrence of urinary acid mucopolysaccharides in the Hurler syndrome. Proc Nati Acad Sci U S A 43(6):443-446

Fujiwara K, Yonenobu K, Ebara S, Yamashita K, Ono K (1989) The prognosis of surgery for cervical compression myelopathy. An analysis of the factors involved. J Bone Joint Surg Br 71(3):393-398

Fukushima T, Ikata T, Taoka Y, Takata S (1991) Magnetic resonance imaging study on spinal cord plasticity in patients with cervical compression myelopathy. Spine 16(10 Suppl):S534-S538

Hendriksz CJ, Al-Jawad M, Berger KI, Hawley SM, Lawrence R, Mc Ardle C, Summers CG, et al (2012) Clinical overview and treatment options for non-skeletal manifestations of mucopolysaccharidosis type IVA. J Inherit Metab Dis doi:10.1007/s10545-012-9459-0

Herzog RJ, Wiens JJ, Dillingham MF, Sontag MJ (1991) Normal cervical spine morphometry and cervical spinal stenosis in asymptomatic professional football players. Plain film radiography, multiplanar 
computed tomography, and magnetic resonance imaging. Spine (Phila Pa 1976) 16(1991):S178-S186

Hinck V, Hopkins C, Savara B (1962) Sagittal diameter of the cervical spinal canal in children. Radiology 79:97-108

Hughes DG, Chadderton RD, Cowie RA, Wraith JE, Jenkins JP (1997) MRI of the brain and craniocervical junction in Morquio's disease. Neuroradiology 39(5):381-385

Hukuda S, Kojima Y (2002) Sex discrepancy in the canal/body ratio of the cervical spine implicating the prevalence of cervical myelopathy in men. Spine 27(3):250-253

Ishikawa M, Matsumoto M, Fujimura Y, Chiba K, Toyama Y (2003) Changes of cervical spinal cord and cervical spinal canal with age in asymptomatic subjects. Spinal Cord 41(3):159-163

Kameyama T, Hashizume Y, Ando T, Takahashi A (1994) Morphometry of the normal cadaveric cervical spinal cord. Spine 32(18):2077-2081

Kameyama T, Hashizume Y, Sobue G (1996) Morphologic features of the normal human cadaveric spinal cord. Spine 21(11):1285-1290

Kato F, Yukawa Y, Suda K, Yamagata M, Ueta T (2012) Normal morphology, age-related changes and abnormal findings of the cervical spine. Part II: magnetic resonance imaging of over 1200 asymptomatic subjects. Eur Spine J 21:1499-1507 doi:10.1007/ s00586-012-2176-4

Kessler JT (1975) Congenital narrowing of the cervical spinal canal. J Neurol Neurosurg Psychiatry 38(12):1218-1224

Koyanagi T, Hirabayashi K, Satomi K, Toyama Y, Fujimura Y (1993) Predictability of operative results of cervical compression myelopathy based on preoperative computed tomographic myelography. Spine 18(14):1958-1963

Matsumoto M, Toyama Y, Ishikawa M, Chiba K, Suzuki N, Fujimura $Y(2000)$ Increased signal intensity of the spinal cord on magnetic resonance images in cervical compressive myelopathy. Does it predict the outcome of conservative treatment? Spine 25(6):677682
Morquio L (1929) Sur une forme de dystrophie osseuse familiale. Arch Med Enfants 32:129-140

Northover H, Cowie RA, Wraith JE (1996) Mucopolysaccharidosis type IVA (Morquio syndrome): a clinical review. J Inherit Metab Dis 19:357-365

Pavlov H, Torg JS, Robie B, Jahre C (1987) Cervical spinal stenosis: determination with vertebral body ratio method. Radiology 164(3):771-775

Robinson MD, Northrup B, Sabo R (1990) Cervical spinal canal plasticity in children as determined by the vertebral body ratio technique. Spine 15(10):1003-1005

Solanki G. (2011) Discussion: Guidelines for neuroradiologists and surgery. MPS VI Cervical Cord Compression Advisory Board Meeting; March 15, 2011; Vancouver, British Columbia, Canada

Stevens JM, Kendall BE, Crockard HA, Ransford A (1991) The odontoid process in Morquio-Brailsford's disease. The effects of occipitocervical fusion. J Bone Joint Surg Br 73(5):851-858

Tierney RT, Maldjian C, Mattacola CG, Straub SJ, Sitler MR (2002) Cervical spine stenosis measures in normal subjects. J Athl Train 37(2):190-193

Tomatsu S, Montaño AM, Oikawa H et al (2011) Mucopolysaccharidosis type IVA (Morquio A disease): clinical review and current treatment. Curr Pharm Biotechnol 12:931-945

Torg JS, Corcoran TA, Thibault LE, Pavlov H, Sennett BJ, Naranja RJ, Priano S (1997) Cervical cord neurapraxia: classification, pathomechanics, morbidity, and management guidelines. J Neurosurg 87(6):843-850

Wraith JE (1995) The mucopolysaccharidosis: a clinical review and guide to management. Arch Dis Child 72:263-267

Yanase M, Matsuyama Y, Hirose K, Takagi H, Yamada M, Iwata H, Ishiguro N (2006) Measurement of the cervical spinal cord volume on MRI. J Spinal Disord Tech 19(2):125-129 doi:10.1097/ 01.bsd.0000181294.67212.79 